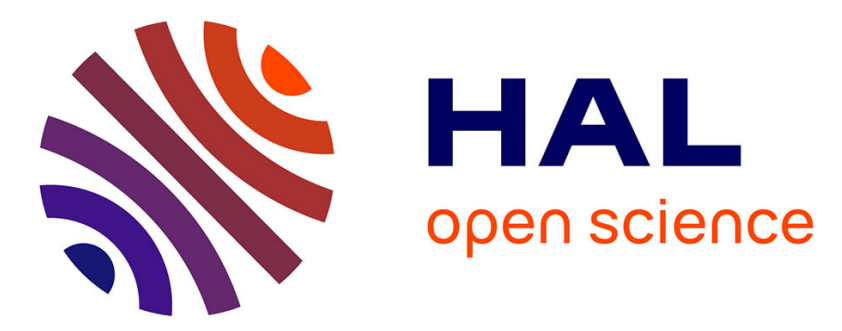

\title{
Effects of a Supplementation during Exercise and Recovery
}

Claire Thomas, Stéphane Perrey, H. Ben Saad, M. Delage, A. M. Dupuy, J. P. Cristol, Jacques Mercier

\section{- To cite this version:}

Claire Thomas, Stéphane Perrey, H. Ben Saad, M. Delage, A. M. Dupuy, et al.. Effects of a Supplementation during Exercise and Recovery. International Journal of Sports Medicine, 2007, 28 (8), $10.1055 / \mathrm{s}-2007-965021$. hal-01587689

\section{HAL Id: hal-01587689 https: / hal-insep.archives-ouvertes.fr/hal-01587689}

Submitted on 14 Sep 2017

HAL is a multi-disciplinary open access archive for the deposit and dissemination of scientific research documents, whether they are published or not. The documents may come from teaching and research institutions in France or abroad, or from public or private research centers.
L'archive ouverte pluridisciplinaire HAL, est destinée au dépôt et à la diffusion de documents scientifiques de niveau recherche, publiés ou non, émanant des établissements d'enseignement et de recherche français ou étrangers, des laboratoires publics ou privés. 


\section{Effects of a Supplementation during Exercise and Recovery}

Authors

Affiliations
C. Thomas $^{1,2}$, S. Perrey ${ }^{3}$, H. Ben Saad ${ }^{1}$, M. Delage ${ }^{4}$, A. M. Dupuy ${ }^{4}$, J. P. Cristol ${ }^{4}$, J. Mercier ${ }^{1,5}$

${ }^{1}$ Université Montpellier 1, UFR Médecine, EA 701, Montpellier, France

2 Université Evry Val d'Essonne, LEPHE EA3872, UFR SFA, Departement STAPS, Evry, France

${ }^{3}$ Laboratoire Efficience et Déficience Motrice, Université Montpellier 1, Montpellier, France

${ }^{4}$ Laboratoire de Biochimie des Lipides et du Stress Oxydant, CHU, Montpellier, France

${ }^{5}$ INSERM, ERI 25, France
Key words

- supramaximal exercise

- fatigue index

- maximal blood lactate

- oxidative damage accepted after revision May 29, 2006

\section{Bibliography}

DOI 10.1055/s-2007-965021

Published online 2007

Int J Sports Med ๑ Georg Thieme Verlag KG Stuttgart .

New York • ISSN 0172-4622

Correspondence

Dr. Claire Thomas, PhD

Université Evry Val d'Essonne

UFR SFA, EA 3872,

Departement STAPS

91000 Evry

France

thomasclaire@wanadoo.fr

\section{Abstract \\ $\nabla$}

The present study was designed to investigate whether a protein hydrolysate enriched in branched chain amino acids and antioxidants, trace and mineral elements, and vitamins would affect performance and fatigue. Eighteen sportsmen underwent testing before and after 28 days supplementation with either treatment in protein hydrolysate or placebo. Testing included exhaustive aerobic and anaerobic exercises with determination of blood lactate concentration through exercise and recovery and antioxidant status, but also measurements of maximal oxidative capacity $\left(\dot{\mathrm{V}}_{\max }\right)$ and citrate synthase activity (CS) from a resting muscle biopsy. Protein hydro-

\section{Introduction}

$\nabla$

A variety of nutritional supplements are widely used by athletes [32], not for gain performance but for health reasons. Most nutritional supplements can be categorized as potential energy sources, anabolic enhancers, or recovery aids. They include vitamins, minerals, proteins, carbohydrates, omega- 3 amino acids, creatine and other energy supplements [33].

Research has consistently shown that supplementation with iron and magnesium, which are involved in some biochemical processes, may prevent the decline in iron and magnesium status associated with training loads [5]. In addition, dietary antioxidants, such as vitamins $\mathrm{A}, \mathrm{C}$ and $\mathrm{E}$ [7] and trace-elements like selenium [21], zinc, copper, chromium, and manganese, may prevent the oxidative stress. Although oxidative stress is present even at rest, acute exercise and training exacerbate it [22] and can overwhelm the capacity to detoxify reactive oxygen species, and so produce oxidative damage; thus, an adequate lysate resulted in a significant decrease in fatigue indices, without affecting performances. A significant increase in enzymatic antioxidant and a decrease in oxidative damage were observed at rest after treatment but not with a placebo. Decrease in maximal blood lactate and improvement of blood lactate removal were only observed after protein hydrolysate treatment. Furthermore, CS increased significantly, whereas no change was observed in $\dot{\mathrm{V}}_{\text {max }}$. In conclusion, this protein hydrolysate treatment induced adaptations that may promote a decrease in fatigue during exercises, potentially explained by changes in parameters used to represent oxidative damage and antioxidant status at rest and changes in lactate metabolism. supply of antioxidants could be of interest to overcome these transient problems.

Others supplements for athletes include various protein and branched chain amino acid (BCAA) products $[24,26]$. These may serve as anabolic agents by optimizing muscle mass - crucial in strength-related sports, but also as a potential energy source during aerobic exercise [36]. Several studies have also pointed out that BCAA uptake and oxidation increase with increasing plasma concentrations [13] due to pre-exercise BCAA ingestion during exercise [36] and during recovery [3]. Moreover, it is well established that alanine release increases during exercise [4], with greater amounts of alanine released during exercise following a BCAA trial than a control trial [20]. Alanine production involves the addition of the amino acid group from the glutamate issue of BCAA to pyruvate, and could be linked to lactate metabolism, particularly when exhaustive exercise is carried out. Lower lactate production would, therefore, be predicted after oral glutamate ingestion. In contrast, Mourtzakis and Graham [25] showed no effect of BCAA administra- 


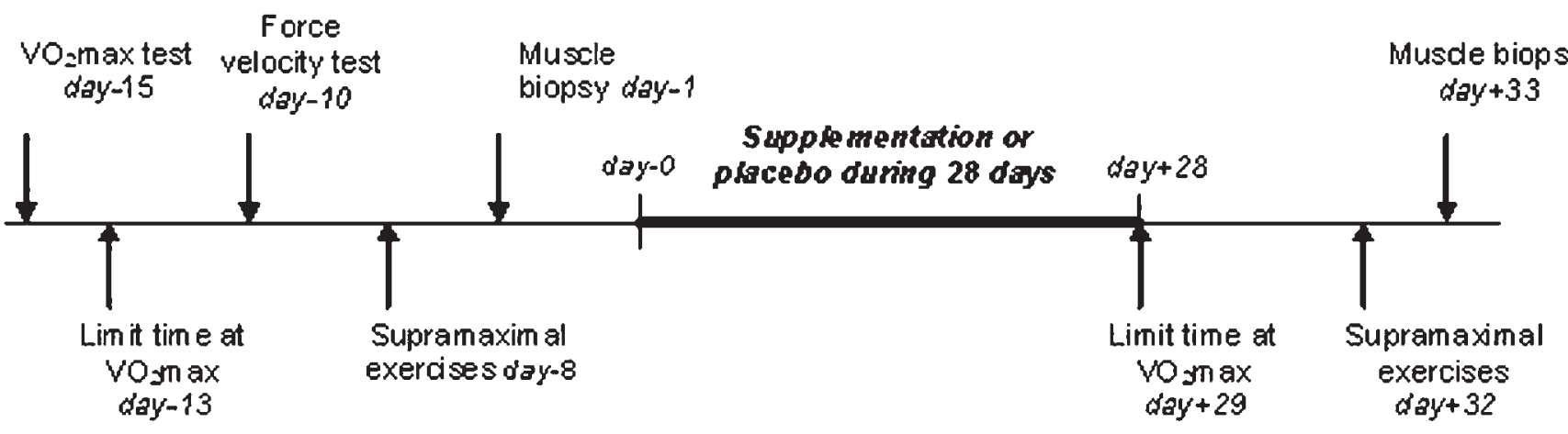

Fig. 1 Experimental design.

Table 1 Characteristics of the subjects in the treatment $(n=9)$ and placebo $(n=9)$ groups. Values are presented as mean $\pm S E$

\begin{tabular}{|c|c|c|c|c|c|}
\hline & Age (years) & Height $(\mathrm{cm})$ & Mass (kg) & Body fat $(\%)$ & $\dot{\mathrm{v}} \mathrm{O}_{2 \max }\left(\mathrm{mL} \cdot \mathrm{min}^{-1} \cdot \mathrm{kg}^{-1}\right)$ \\
\hline Treatment group & $25.0 \pm 1.2$ & $182.1 \pm 2.0$ & $73.9 \pm 3.4$ & $8.4 \pm 1.8$ & $61.2 \pm 4.0$ \\
\hline Placebo group & $27.1 \pm 2.5$ & $176.4 \pm 1.5$ & $74.8 \pm 3.8$ & $10.4 \pm 2.2$ & $59.7 \pm 2.5$ \\
\hline
\end{tabular}

tion on lactacidemia after a 15 -min cycling bout at $85 \%$ of maximal oxygen uptake $\left(\dot{\mathrm{V}}_{2 \max }\right)$, whereas MacLean et al. [20] observed a decrease in lactacidemia after 90 min of dynamic knee extensor exercise following BCAA administration. In addition, after chronic BCAA ingestion, Vukovich et al. [37] and De Palo et al. [8] have observed a decrease in blood lactate concentration at the end of a 30-s Wingate test and following 60 min of physical exercise at $75 \%$ of $\dot{\mathrm{VO}}_{2 \max }$, respectively, which may reflect an improvement of BCAA use.

We, therefore, hypothesized that a mixture of protein hydrolysate enriched with branched chain amino acids, antioxidants, trace and mineral elements and vitamins could reduce oxidative damage and decrease blood lactate concentration after supramaximal exercise. In addition, we hypothesized that enhanced blood lactate removal with changes in muscle oxidative capacity may also be observed. In an attempt to verify these hypotheses, we investigated whether this mixture had an effect on muscle oxidative capacity, on blood lactate accumulation after continuous and intermittent supramaximal exercises, and on oxidative damage. The effects of this mixture on the performance of supramaximal exercise time to fatigue test at $\dot{\mathrm{VO}}_{2 \max }$ and fatigue indices were also evaluated. Therefore, in order to test the effects of this nutritional supplement, different types of supramaximal exercises were voluntary targeted to induce high exhaustion in the subjects and to modify strongly physiological parameters like blood lactate concentration.

\section{Materials and Methods \\ $\nabla$}

Subjects

Eighteen male volunteers participated in this study. Subjects were included in the study if they had less than $25 \%$ body fat, were nonsmokers, diet and weight stable, and free of injury/disease as determined by physical examination. Informed consent was obtained from all the subjects after explanation of the nature and risks involved in participation in the experiments. The study was approved by the local ethics committee and conformed to the Declaration of Helsinki regarding the use of human subjects.
Subjects with different training status were deliberately targeted for this study. The group consisted of untrained/recreational subjects $(n=9)$, and athletes $(n=9)$ specialized in middleand long-distance running. These subgroups were determined from the subjects' responses to a physical activity questionnaire and their maximal oxygen uptake $\left(\dot{\mathrm{V}}_{2 \text { max }}\right)$ values, as previously described [35]. The untrained subjects had a normal level of physical activity without any athletic training, whereas the recreational athletes trained $2-3$ times per week but did not compete. The middle-distance runners competed in $800-\mathrm{m}$ and 1500-m events and trained 5-6 times per week. Their training included frequent high-intensity sessions alternating with endurance sessions. The long-distance runners competed in events of $5 \mathrm{~km}$ or more. They trained 8-10 times per week and ran an average of $110 \mathrm{~km}$ per week, including high-intensity workouts with 400- to 3000-m intervals and continuous running (10$25 \mathrm{~km}$ ). Before and during the study, all subjects performed their usual physical activity.

\section{Experimental design ( $\bigcirc$ Fig. 1)}

Before supplementation, all subjects came to the laboratory for four exercise test sessions, as well as for the skeletal muscle biopsy. At least $48 \mathrm{~h}$ separated the exercise test sessions; the muscle biopsy was performed one week later, after at least one day in resting conditions (i.e., without physical activity). The subjects performed all exercise tests at a laboratory temperature of $22^{\circ} \mathrm{C}$. An initial laboratory visit was scheduled to obtain data on physical characteristics and individual maximal oxygen consumption. During the second visit, subjects performed a time to fatigue test at $\mathrm{VO}_{2 \max }$ on the treadmill. During the third visit, subjects were familiarized with the testing procedure on the cycleergometer and performed a force-velocity test. During the fourth visit, subjects performed a 1-min all-out exercise followed by $60 \mathrm{~min}$ of passive recovery, followed by 10 short cycling sprints separated by $30-s$ recovery intervals. Finally, they were randomly assigned to one of two groups ( Table 1 ), taking either treatment constituted of a mixture of protein hydrolysate enriched in branched chain amino acid, antioxidants, vitamins, and minerals or a placebo. This study was conducted in a doubleblind fashion. Following the supplementation period, subjects 
Table 2a Details of the nutritional treatment given to the treatment group

\begin{tabular}{|lcc|}
\hline Mean nutritional analysis & Per $\mathbf{1 0 0 ~ g}$ & Per sachet (13 g) \\
\hline Energetic values & $370 \mathrm{kcal}(1546 \mathrm{~kJ})$ & $48 \mathrm{kcal}(201 \mathrm{~kJ})$ \\
\hline Proteins & $63.8 \mathrm{~g}$ & $8.3 \mathrm{~g}$ \\
\hline Carbohydrates & $15.2 \mathrm{~g}$ & $2.0 \mathrm{~g}$ \\
\hline Lipids & $6.0 \mathrm{~g}$ & $0.8 \mathrm{~g}$ \\
\hline Sodium & $1083 \mathrm{mg}$ & $141 \mathrm{mg}$ \\
\hline Potassium & $199 \mathrm{mg}$ & $26 \mathrm{mg}$ \\
\hline Calcium & $294 \mathrm{mg}$ & $38 \mathrm{mg}$ \\
\hline Magnesium & $1457 \mathrm{mg}$ & $189 \mathrm{mg}$ \\
\hline Iron & $108 \mathrm{mg}$ & $14 \mathrm{mg}$ \\
\hline Zinc & $115 \mathrm{mg}$ & $15 \mathrm{mg}$ \\
\hline Copper & $15.4 \mathrm{mg}$ & $2 \mathrm{mg}$ \\
\hline Manganese & $26.9 \mathrm{mg}$ & $3.5 \mathrm{mg}$ \\
\hline Chromium & $192 \mu \mathrm{g}$ & $25 \mu \mathrm{g}$ \\
\hline Selenium & $577 \mu \mathrm{g}$ & $75 \mu \mathrm{g}$ \\
\hline Vitamin C & $923 \mathrm{mg}$ & $120 \mathrm{mg}$ \\
\hline Vitamin E & $76.9 \mathrm{mg}$ & $10 \mathrm{mg}$ \\
\hline Niacin & $138.5 \mathrm{mg}$ & $18 \mathrm{mg}$ \\
\hline Vitamin B12 & $7.7 \mu \mathrm{g}$ & $1 \mu \mathrm{g}$ \\
\hline Folic acid & $1.5 \mathrm{mg}$ & $0.2 \mathrm{mg}$ \\
\hline Thiamin & $10.8 \mathrm{mg}$ & $1.4 \mathrm{mg}$ \\
\hline Riboflavin & $12.3 \mathrm{mg}$ & $1.6 \mathrm{mg}$ \\
\hline Vitamin B6 & $15.4 \mathrm{mg}$ & $2 \mathrm{mg}$ \\
\hline Biotin & $1.1 \mathrm{mg}$ & $0.15 \mathrm{mg}$ \\
\hline Vitamin A & $20492 \mathrm{UI}$ & $2664 \mathrm{UI}$ \\
\hline
\end{tabular}

again performed the time to fatigue test at $\mathrm{VO}_{2 \max }$ and both supramaximal exercise tests; $24 \mathrm{~h}$ after the last visit, a second skeletal muscle biopsy was obtained. For this second biopsy, we voluntary chose to take it $24 \mathrm{~h}$ after the last exercise session in order to have subjects in the same resting physiological conditions than before treatment.

\section{Supplementation}

All subjects received either a treatment or a placebo, which was contained in an indistinguishable sachet, for 28 days in addition to their normal diet. Sachets were provided in a randomized, double-blind manner. Neither the patient nor the researchers were aware which treatment (protein hydrolysate or placebo) each subject was receiving. All subjects consumed two oral sachets per day, one sachet before breakfast and one sachet before dinner. The preparation content per sachet for the treatment is detailed in Tables 2 a, b (Actibiomax ${ }^{\circledast}$, MERCK-MF Richelet Laboratories, Paris, France). The placebo contained neither nutrients nor vitamin supplementation, but contained orange flavor, salts, citric acid, and an artificial sweetener (Prodietic, St. Maximin, France). In consequence, the placebo was identical in amount, aspect and taste as for the treatment group.

Before the beginning of the study, subjects were told to comply carefully with the protocol and to go on with their normal and stable diet and their usual physical activity. Following the end of the protocol, we were informed that the treatment group was constituted of 5 untrained/recreational subjects and 4 athletes.

\section{Anthropometry}

Weight and height measurements were performed and BMI was calculated as weight in kilograms divided by height in meters squared $\left(\mathrm{kg} / \mathrm{m}^{2}\right)$. Impedance in body tissue to the flow of an applied alternative current was measured by bioelectrical impedance analysis and the values obtained were used to estimate body composition (body fat mass, percentage of body fat) [19].
Table $\mathbf{2 b}$ Amino acid composition

\begin{tabular}{|c|c|c|}
\hline & Per $100 \mathrm{~g}$ & Per sachet (13 g) \\
\hline Isoleucine & $4.21 \mathrm{~g}$ & $0.55 \mathrm{~g}$ \\
\hline Leucine & $8.24 \mathrm{~g}$ & $1.07 \mathrm{~g}$ \\
\hline Lysine & $6.14 \mathrm{~g}$ & $0.80 \mathrm{~g}$ \\
\hline Methionine & $1.93 \mathrm{~g}$ & $0.25 \mathrm{~g}$ \\
\hline Cysteine & $2.55 \mathrm{~g}$ & $0.33 \mathrm{~g}$ \\
\hline Phenylalanine & $2.79 \mathrm{~g}$ & $0.36 \mathrm{~g}$ \\
\hline Tyrosine & $2.66 \mathrm{~g}$ & $0.35 \mathrm{~g}$ \\
\hline Alanine & $3.32 \mathrm{~g}$ & $0.43 \mathrm{~g}$ \\
\hline Threonine & $3.58 \mathrm{~g}$ & $0.47 \mathrm{~g}$ \\
\hline Tryptophan & $1.49 \mathrm{~g}$ & $0.19 \mathrm{~g}$ \\
\hline Histidine & $1.21 \mathrm{~g}$ & $0.16 \mathrm{~g}$ \\
\hline Arginine & $1.69 \mathrm{~g}$ & $0.22 \mathrm{~g}$ \\
\hline Aspartic acid & $7.65 \mathrm{~g}$ & $0.99 \mathrm{~g}$ \\
\hline Serine & $2.80 \mathrm{~g}$ & $0.36 \mathrm{~g}$ \\
\hline Proline & $3.49 \mathrm{~g}$ & $0.45 \mathrm{~g}$ \\
\hline Glycine & $3.07 \mathrm{~g}$ & $0.40 \mathrm{~g}$ \\
\hline Glutamic acid & $12.50 \mathrm{~g}$ & $1.62 \mathrm{~g}$ \\
\hline Valine & $3.86 \mathrm{~g}$ & $0.50 \mathrm{~g}$ \\
\hline Essential amino acids & $28.77 \mathrm{~g}$ & $3.74 \mathrm{~g}$ \\
\hline BCAA & $16.31 \mathrm{~g}$ & $2.12 \mathrm{~g}$ \\
\hline
\end{tabular}

All bioelectrical impedance measurements were performed by a multi-frequency $(1,5,10,50,100 \mathrm{kHz})$ device (Human IM-Scan from Dietosystem, Milan, Italy). Analysis was performed with the software Master 1.0 (Dietosystem, Milan, Itlay) provided by the manufacturer.

\section{Assessment of $\dot{\mathrm{VO}}_{2 \text { max }}$}

At the beginning of the study, all subjects underwent an incremental maximal exercise test on a treadmill (LE 200 CE Jaeger, Hoechberg, Germany) to determine $\dot{\mathrm{VO}}_{2 \max }$ and the minimal speed associated with $\dot{\mathrm{V}} \mathrm{O}_{2 \max }\left(\mathrm{v}_{\mathrm{V}} \mathrm{V}_{2 \max }\right)$. During the test, oxygen uptake $\left(\dot{\mathrm{VO}}_{2}\right)$, carbon dioxide production $\left(\dot{\mathrm{V}} \mathrm{CO}_{2}\right)$, and minute ventilation (VE) were measured by means of an open circuit metabolic cart (Oxycon Pro, Jaeger, Hoechberg, Germany). Heart rate (HR) was measured and recorded continuously with a heart rate monitor (Sport Tester PE 3000, Polar, Kempele, Finland). The exercise test increments were designed to exhaust the subject within 10-15 min. Each stage consisted of a 2-min exercise period and increased by $1 \mathrm{~km} \cdot \mathrm{h}^{-1}$.

\section{Time to fatigue at $\dot{\mathrm{V}}_{2 \max }$}

The time to fatigue test at $\dot{\mathrm{VO}}_{2 \max }$ was performed on the treadmill at least $48 \mathrm{~h}$ after the assessment of $\dot{\mathrm{VO}}_{2 \max }$. After a 10 -min warm-up at an average intensity of $60 \%$ of $\dot{\mathrm{VO}}_{2 \max }$ and 5 min of passive recovery, the exercise intensity was increased so that each subject reached his $\mathrm{vVO}_{2 \max }$ in less than $30 \mathrm{~s}$ and then continued at that speed until exhaustion. Time to fatigue was recorded in seconds. All cardiorespiratory parameters described previously were recorded throughout the test.

\section{Supramaximal exercise tests}

Subjects performed all exercise tests at the laboratory at $22^{\circ} \mathrm{C}$ on a standard friction-loaded cycleergometer (type $818 \mathrm{E}$, Monark, Stockholm, Sweden) specifically equipped with both a strain gauge (Interface MFG type, Scottsdale, AZ, USA) and an optical encoder (Hengstler type RIS IP50, Aldingen, Germany). The strain gauge and the optical encoder measured the friction force applied to the belt and the flywheel displacement, respectively. The velocity of the flywheel was determined using a first order 
derivation of the flywheel displacement and the power output was calculated from the product of total force and flywheel velocity. Values of velocity, force and power output were collected at $50 \mathrm{~Hz}$ and were stored to a computer for subsequent analysis. For all tests, subjects were in the seated position during exercise and in the supine position on a bed during rest and recovery. All tests started with the front pedal crank elevated at approximately $45^{\circ}$ to the horizontal to facilitate the best starting push. All tests were performed between 8 and 10 a.m. after an overnight fast.

\section{Session I}

The first test was a force-velocity test. It consisted of the repetition of short maximal sprints using different braking forces after a 5-min warm-up on the cycleergometer. The duration of each sprint was fixed at $8 \mathrm{~s}$, this time being sufficient for a vigorously motivated subject to attain his maximal pedalling rate as rapidly as possible after the starting signal. All subjects started the test randomly against friction loads corresponding to $0.4,0.6$, or $0.8 \mathrm{Nkg}^{-1}$ of body weight. Each sprint was separated by at least 5 min of rest. At the start signal, the subjects were told to remain on the saddle and to pedal as fast as possible to reach maximal pedalling rate. Each subject was verbally encouraged throughout each sprint. These sprints allowed us to familiarize the subjects with the cycleergometer and to calculate the optimal friction load against which the subjects had to perform during the second session. From this, velocity, force, and power output values (averaged per half-pedal revolution) recorded during the acceleration phase of the three sprints were used to determine the individual force- and power-velocity relationships. Optimal values of friction force and velocity at which the highest power output was performed were determined from these relationships.

\section{Session II}

The all-out test consisted of $1 \mathrm{~min}$ of supramaximal cycling against the optimal friction load determined previously during the force-velocity test. The subjects were requested to pedal as fast as possible from the start of exercise and were verbally encouraged to maintain maximal pedalling speed throughout the 1-min duration of the test. Subjects were informed of the time every $15 \mathrm{~s}$, and given a countdown for the final $5 \mathrm{~s}$. Mean (W), peak and end $(\mathrm{W})$ power output values were then calculated ( $\mathrm{P}_{\text {meanAO, }} \mathrm{P}_{\text {maxAo, }}$ and $\mathrm{P}_{\text {EndAO, }}$, respectively). Anaerobic performances were determined from the $P_{\text {meanAo values. The fatigue }}$ index of the all-out test $\left(\mathrm{FI}_{\mathrm{AO}}\right)$ was calculated as the percentage of decline from peak to end power output values for each subject. All subjects recovered in the supine position for $1 \mathrm{~h}$.

Subjects then performed a 6-min warm-up on the cycleergometer at a moderate power output. After a 5-min rest in a sitting position, the subjects performed ten consecutive 10-s sprints separated by 30 -s recovery intervals against a friction load corresponding to $50 \%$ of the optimal value of friction force for each subject [28]. The fatigue index of the sprints $\left(\mathrm{FI}_{\text {sprint }}\right)$ for mean power output was calculated for the ten sprints from the negative, linear slope of the individual power output-time relationships.

\section{Blood samples for determination of plasma biochemical parameters}

Blood samples were drawn from a 32-mm catheter placed into a superficial forearm vein. Venous blood samples, used for determination of plasma oxidative damage and antioxidant parameters, were collected at different times in tubes containing hepa- rin: at rest, at $0,30,60$ min of recovery of the all-out test (and $24 \mathrm{~h}$ after test). Blood samples were immediately centrifuged (2500 rpm for $10 \mathrm{~min}$ at $4{ }^{\circ} \mathrm{C}$ ), and the supernatant was stored at $-80^{\circ} \mathrm{C}$ until subsequent analysis.

\section{Marker of systemic oxidative damage}

Thiobarbituric acid reactive substances (TBARs) were determined spectrophotometrically by the method described by Yagi et al. [39]. The final result, expressed as micromoles of TBARs formed per liter of plasma, provides a marker of lipid peroxidation and was used as a marker of systemic oxidative damage.

\section{Marker of the enzymatic antioxidant system}

Plasma glutathione peroxidase (GSH-Px) was determined according to the method of Flohe and Gunzler [10].

\section{Markers of the non-enzymatic antioxidant system}

Total antioxidant capacity (TAC) was assayed using the trolox equivalent antioxidant capacity (TEAC) with a quantitative colorimetric technique in a kit according to the manufacturer's instructions (Kit NX2331 Randox, Mauguio, France). Plasma vitamin E concentrations were measured by high performance liquid chromatography (HPLC) according to the method described by Cachia et al. [6].

\section{Blood lactate concentration}

The venous blood samples, used for determination of plasma lactate, were also collected in tubes containing heparin. For the all-out test, blood was sampled at rest, just after the warm-up, and at $0,1,2,3,4,5,6,7,8,9,10,12,15,20,30,40,50$, and $60 \mathrm{~min}$ of recovery. For the repeated cycling sprints, blood was sampled just after sprint number 1, 3, 5, 7, and 10, and finally at 3,5 , and 7 min of recovery.

\section{Blood lactate assay}

Blood lactate concentration was analyzed enzymatically according to the method of Gutmann and Wahlefeld [14]. Briefly, a $200 \mu \mathrm{L}$ aliquot of the blood sample was immediately mixed with $800 \mu \mathrm{L}$ of ice-cold $7 \%$ perchloric acid and centrifuged at $1500 \mathrm{~g}$ for $10 \mathrm{~min}$ at $4{ }^{\circ} \mathrm{C}$. The supernatant was stored at $-80^{\circ} \mathrm{C}$. For the analysis, an aliquot of the resulting supernatant was mixed with $\mathrm{NaOH} 2 \mathrm{~N}$. The reaction began with addition of nicotinamide adenine dinucleotide (NAD) and lactate deshydrogenase (LDH) in a glycine/hydrazine buffer. The reaction followed the formation of $\mathrm{NADH}_{2}$ at $340 \mathrm{~nm}$.

\section{Lactate kinetics analysis}

The venous blood lactate concentrations were determined during the recovery periods following the supramaximal exercise test and each individual curve was fitted using the following biexponential equation [11]: $[\mathrm{La}(\mathrm{t})]_{\mathrm{v}}=\mathrm{La}(0)+\mathrm{A}_{1}\left(1-\mathrm{e}^{-\gamma 1 \mathrm{t}}\right)+\mathrm{A}_{2}(1-$ $\mathrm{e}^{-\gamma 2 \mathrm{t}}$, where $\mathrm{La}(\mathrm{t})$ and $\mathrm{La}(0)$ are the measured lactate concentration in venous blood at time $t$ after the end of exercise and at the beginning of the recovery; $A_{1}$ and $A_{2}$ (in millimoles per liter) are the amplitudes of the two exponential components, and $\gamma_{1}$ and $\gamma_{2}$ (per minute) are their velocity constants, respectively.

The individual parameters of the bi-exponential function were fitted by means of an iterative nonlinear technique, using DataFit 6.0 software to determine values of $A_{1}, A_{2}, \gamma_{1}$, and $\gamma_{2}$. The percentage of the variance explained by the use of the bi-exponential curve fit was determined by correlation of the observed and 
the predicted $[\mathrm{La}(\mathrm{t})]_{\mathrm{V}}$ at each time and by squaring of the Pearson product correlation coefficient.

\section{Skeletal muscle biopsy}

Vastus lateralis muscle biopsies were taken by the percutaneous Bergström technique after local anesthesia (xylocaine). No complications were noted following the biopsies. The muscle samples were divided into two portions. One portion was immediately frozen in liquid nitrogen and stored at $-80^{\circ} \mathrm{C}$ until enzymatic determination. The other portion was used for the in situ respiration studies and was immediately placed in an ice-cold relaxing solution (at ionic strength 160 [potassium methanesulfonate], pH 7.1) containing (mm): EGTA-calcium buffer 10 (free $\mathrm{Ca}^{2+}$ concentration $\left.100 \mathrm{nmol} \cdot \mathrm{L}^{-1}\right)$, Imidazole $20, \mathrm{KH}_{2} \mathrm{PO}_{4} 3$, $\mathrm{MgCl}_{2}$ 1, Taurine 20, Dithiotreitol (DTT) 0.5, MgATP 5, and PhosphoCreatine 15.

The fiber bundles were separated with sharp-ended needles, leaving only small areas of contact, and were incubated in $1 \mathrm{ml}$ of the above solution $\left(4^{\circ} \mathrm{C}\right)$ containing $50 \mu \mathrm{g} \cdot \mathrm{mL}^{-1}$ saponin for 30 min with continuous stirring. In order to completely remove the saponin, the fibers were washed with continuous stirring with relaxing solution for $10 \mathrm{~min}\left(4^{\circ} \mathrm{C}\right)$. In order to remove free ATP, they were then washed with oxygraph solution for $2 \times 5 \mathrm{~min}$ $\left(4^{\circ} \mathrm{C}\right)$. This was of the same composition as the relaxing solution except that MgATP and PCr were replaced $(\mathrm{mm})$ by malate 2 , phosphate 3 , and fatty acid-free bovine serum albumin 2 [pH 7.1]. After washing, the fibers were stored on ice in oxygraph solution until determination of mitochondrial respiration activity.

\section{Muscle analysis}

\section{Mitochondrial respiration}

The respiratory parameters of the total mitochondrial population were studied in situ as previously described $[18,23,34]$ using a Clark electrode (Strathkelvin Instruments, Glasgow, Scotland). Measurements were carried out at $30^{\circ} \mathrm{C}$ with continuous stirring in $3 \mathrm{ml}$ of the oxygraph solution with (mM) glutamate 5 + malate 2 as substrates. ADP-stimulated respiration $\left(\dot{\mathrm{V}}_{\mathrm{ADP}}\right)$ above basal oxygen consumption $\left(\dot{V}_{0}\right)$ was measured by stepwise addition of ADP (2.5 to $2000 \mu \mathrm{m})$. At the end of measurement, we used the cytochrome $\mathrm{c}$ test to investigate the state of the outer mitochondrial membrane [30]. After the following respiratory measurements, the fiber bundles were removed, dried overnight, and weighed the next day. Respiration rates were expressed in micromoles of $\mathrm{O}_{2}$ per minute per gram of dry weight. Maximal ADP-stimulated respiration (Vmax) was calculated using a nonlinear mono-exponential fitting of the Michaelis-Menten equation with DataFit 6.0 software (Oakdale Engineering, Oakdale, PA, USA).

\section{Citrate synthase (CS) activity analysis}

Homogenates for citrate synthase (CS) were prepared in buffer (mM): sucrose 210, EGTA 2, NaCl 40, HEPES 30, EDTA 5, and phenylmethylsulfonyl fluoride 2 , $\mathrm{pH} 7.4$ and stored at $-80^{\circ} \mathrm{C}$. CS activity was assayed according to Srere [31].

\section{Statistical analysis}

Descriptive statistics are expressed as means \pm standard error (SE). Student's $t$-test was used to compare both groups for age, height, mass, body-fat and $\dot{\mathrm{V}}_{2 \max }$. Exercise performance data ( $\mathrm{P}_{\text {mean }}, \mathrm{FI}_{\mathrm{AO}}, \mathrm{FI}_{\text {Sprint }}$, time limit) and physiological data (maximal blood lactate concentration during the all-out exercise, CS activ-
Table 3 Individual values of time limit exercise performance at $\dot{\mathrm{V}}_{2 \max }$ on a treadmill

\begin{tabular}{|lcclll|}
\hline & \multicolumn{2}{l}{ Treatment } & & \multicolumn{2}{l|}{ Placebo } \\
\hline Subjects & Pre & Post & Subjects & Pre & Post \\
\hline 1 & 4.1 & 3.4 & $1^{\prime}$ & 6.0 & 6.0 \\
\hline 2 & 4.2 & 4 & $2^{\prime}$ & 3.1 & 3.8 \\
\hline 3 & 3.3 & 4 & $3^{\prime}$ & 4.1 & 5.0 \\
\hline 4 & 7.1 & 12.1 & $4^{\prime}$ & 4.0 & 4.5 \\
\hline 5 & 5.0 & 5.1 & $5^{\prime}$ & 5.9 & 8.0 \\
\hline 6 & 11.6 & 14 & $6^{\prime}$ & 6.0 & 4.9 \\
\hline 7 & 8.4 & 9 & $7^{\prime}$ & 3.9 & 5.0 \\
\hline 8 & 9.0 & 8.0 & $8^{\prime}$ & 4.3 & 5.6 \\
\hline 9 & 4.7 & 4.7 & $9^{\prime}$ & 6.5 & 5.5 \\
\hline Mean \pm SE & $6.4 \pm$ & $7.2 \pm$ & & $5.2 \pm$ & $5.4 \pm$ \\
& 0.9 & 1.3 & & 0.4 & 0.4 \\
\hline
\end{tabular}

ity and maximal muscle oxidative capacity) were analyzed by a two-way analysis of variance (ANOVA). The within-group condition was the time (pre-, post-treatment), and the between group condition was the treatment and placebo. Biochemical data (plasma GSH-PX, TBARS, TAC, Vitamin E, and blood lactate concentration during the sprints and recovery) were analyzed by a two-way ANOVA with repeated measures. When a significant $F$ ratio $(p<0.05)$ was obtained, a Student-Newman-Keuls test was used to locate significant mean differences. The concentration of statistical significance was set at $\mathrm{p}<0.05$. The data were analyzed using the statistical package SigmatStat 1.0 (Jandel Scientific, San Rafael, CA, USA).

\section{Results}

$\nabla$

Age, height, mass, \% body fat, and $\dot{\mathrm{VO}}_{2 \max }$ values for treatment and placebo groups are reported in $\bigcirc$ Table 1. No significant differences were observed $(p>0.05)$.

\section{Performances and fatigue indices \\ Time limit exercise performance}

As shown in $\odot$ Table 3, the mean times to exhaustion at $\dot{\mathrm{V}}_{2 \max }$ were $6.4 \pm 0.9 \mathrm{~min}$ and $7.2 \pm 1.3 \mathrm{~min}$ before and after 28 days of supplementation, respectively, and were $5.2 \pm 0.4 \mathrm{~min}$ and $5.4 \pm 0.4 \mathrm{~min}$ before and after placebo, respectively. No significant difference was observed between pre- and post-tests in each group and between treatment and placebo groups in preand post-test $(p>0.05)$.

\section{Mechanical performance during supramaximal exercises}

The values for peak power output and mean power output during the 1-min all-out exercise, and indexes of performance, are given in 0 Table 4. No significant difference was observed between pre- and post-tests in each group and between treatment and placebo groups in pre- and post-tests $(p>0.05)$ for each parameter.

\section{Fatigue indexes during supramaximal exercise}

Fatigue indices during the 1-min all-out test $\left(\mathrm{FI}_{\mathrm{AO}}\right)$ and the 10 short repeated sprints $\left(\mathrm{FI}_{\text {sprint }}\right)$ are also reported in O Table 4. $\mathrm{FI}_{\mathrm{AO}}$ and $\mathrm{FI}_{\text {Sprint }}$ were significantly lower $(\mathrm{p}<0.05)$ in the posttest treatment group, but not in the placebo group; and signifi- 
Table 4 Values of mechanical power output and the fatigue indexes during the 1-min all-out test and the ten cycling sprints in the treatment $(n=9)$ and placebo $(n=9)$ groups. Values are presented as mean $\pm S E$

\begin{tabular}{|lrcrr|} 
& \multicolumn{3}{c}{ Treatment } & \multicolumn{1}{c|}{ Placebo } \\
& \multicolumn{1}{c}{ Pretest } & \multicolumn{1}{c|}{ Post-test } & \multicolumn{1}{l|}{ Pretest } & \multicolumn{1}{c|}{ Post-test } \\
\hline $\mathrm{P}_{\text {MeanAO }}(\mathrm{W})$ & $461 \pm 18$ & $453 \pm 11$ & $451 \pm 17$ & $458 \pm 23$ \\
\hline $\mathrm{P}_{\text {MaxAO }}(\mathrm{W})$ & $1244 \pm 55$ & $1239 \pm 68$ & $1288 \pm 89$ & $1306 \pm 73$ \\
\hline $\mathrm{FI}_{\text {AO }}(\%)$ & $72.8 \pm 2.8$ & $65.7 \pm 2.6 * \S$ & $69.9 \pm 2.9$ & $70.0 \pm 2.9$ \\
\hline $\mathrm{Fl}_{\text {Sprint }}$ & $-12.9 \pm 3.4$ & $-5.5 \pm 2.6 * \S$ & $-12.1 \pm 2.8$ & $-10.2 \pm 2.8$ \\
\hline
\end{tabular}

$\mathrm{P}_{\text {MeanAO }}$ and $\mathrm{P}_{\text {MaxAO }}$ are mean and peak power outputs, respectively. $\mathrm{Fl}_{\mathrm{AO}}$ is the fatigue index of the all-out test for power output calculated as the percentage of decline from peak to end values for each subject. $\mathrm{Fl}_{\text {Sprint }}$ is the fatigue index for mean power output, calculated for the ten sprints from the negative linear slope in power output-time relationships. * Significant difference between pre- and post-test in the treatment group at $p<0.05$. ${ }^{\S}$ Significant difference between treatment and placebo groups in post-test at $\mathrm{p}<0.05$

cant post-test differences $(\mathrm{p}<0.05)$ were also detected between treatment and placebo groups.

Parameters of free radical production and endogenous antioxidants potential

Markers of systemic oxidative damage

Lipid peroxidation, reflected by TBARS concentration, decreased significantly at rest $(\mathrm{p}<0.01)$ in the treatment group after supplementation, whereas no change appeared in the placebo group. However, there were no differences within or between groups $(p>0.05)$ at rest or after exercise.

\section{Markers of the enzymatic antioxidant system}

Plasma GSH-Px increased significantly at rest $(p<0.05)$ in the treatment group after supplementation, whereas no change was observed in the placebo group. A significant difference was observed at rest between the treatment and placebo groups following the supplementation period $(\mathrm{p}<0.05)$. No significant difference $(p>0.05)$ was observed after exercise in either group or between groups at any time during recovery.

\section{Markers of the non-enzymatic antioxidant system}

There were no significant differences in plasma non-enzymatic antioxidant concentrations (vitamin $\mathrm{E}$ and total antioxidant capacity) throughout the post-exercise period and after treatment or placebo ( 0 Tables 3,4 and $\mathbf{5}$ ).

\section{Blood lactate}

Blood lactate recovery curves after supramaximal all-out exercise

The time course of blood lactate concentration during recovery showed the classic biphasic evolution pattern for all subjects. From the end of exercise, blood lactate concentration increased, reached a peak, and, thereafter, decreased progressively. The biexponential model accurately fitted the individual recovery curves obtained after the 1-min all-out exercise. In most cases, the bi-exponential equation accounted for more than $98 \%$ of the variance in the lactate recovery curves. In addition, the fit accuracy for all subjects was similar to that obtained previously [12].

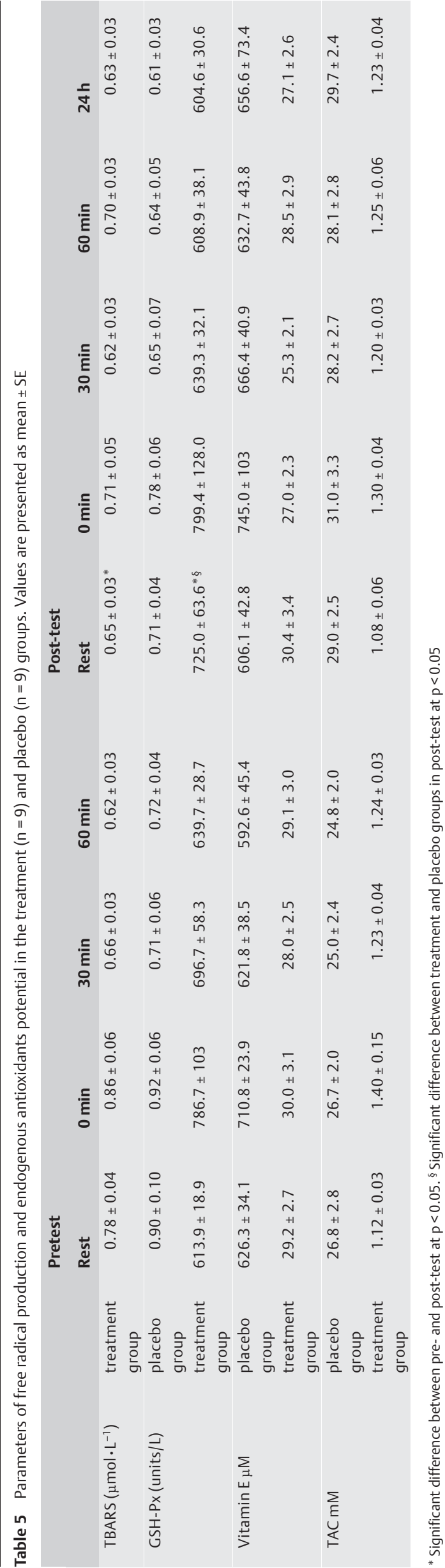




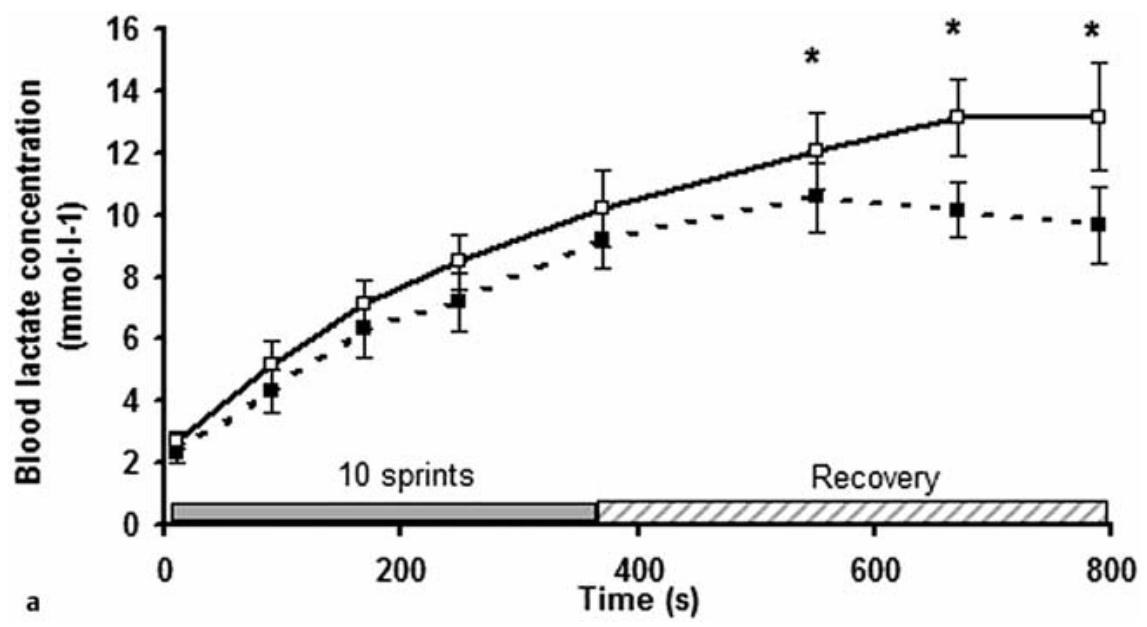

Fig. 2a Venous blood lactate concentrations during and after 10 cycling sprints in pre- (solid line) and post-test (dotted line) in the treatment $(n=9)$ group. ${ }^{*}$ Significant difference between pre- and post-test at $\mathrm{p}<0.05$.

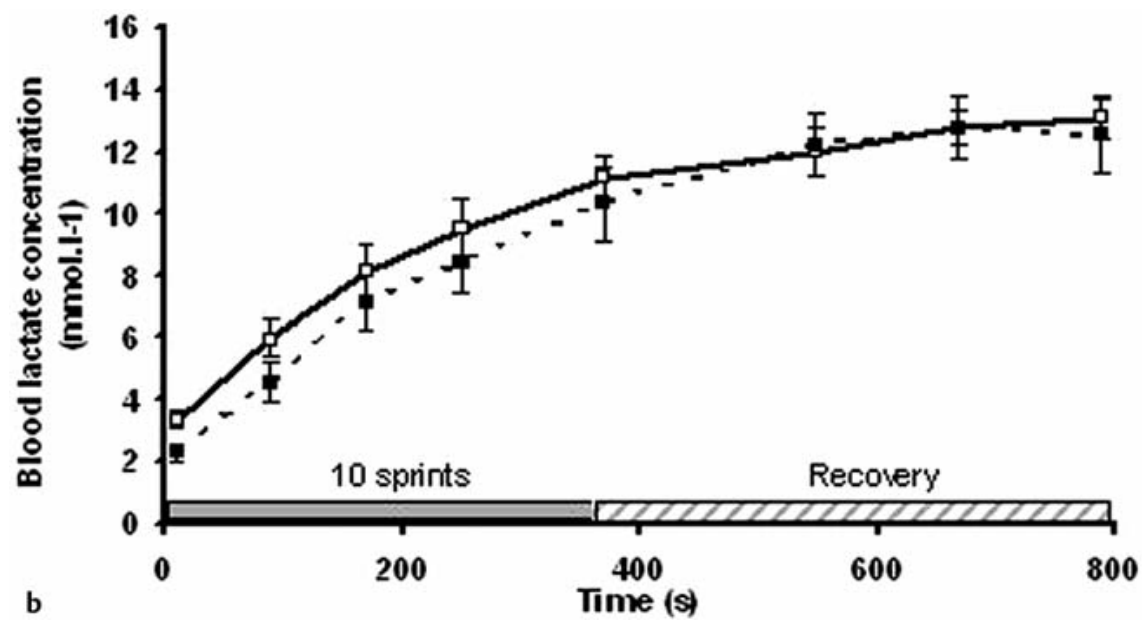

Fig. 2b Venous blood lactate concentrations during and after 10 cycling sprints in pre- (solid line) and post-test (dotted line) in the placebo $(n=9)$ group. ${ }^{*}$ Significant difference between pre- and post-test at $\mathrm{p}<0.05$.

\section{Maximal blood lactate concentration after 1-min all-out exercise}

Maximal blood lactate concentration was significantly lower $(\mathrm{p}<0.05)$ following supplementation after the 1-min all-out exercise in treatment group $\left(13.0 \pm 0.7\right.$ versus $\left.11.3 \pm 0.9 \mathrm{mmol} \cdot \mathrm{L}^{-1}\right)$, whereas no significant difference appeared in placebo group (13.6 \pm 0.9 versus $\left.12.3 \pm 0.8 \mathrm{mmol} \cdot \mathrm{L}^{-1}\right)$. Post-supplementation, there was no significant difference in maximal blood lactate concentration between the treatment and placebo groups. Blood lactate removal ability, determined with the bi-exponential model, was found to be significantly higher $(p<0.05)$ in the treatment group after supplementation $\left(\gamma_{2}=0.025 \pm 0.0056\right.$ versus $0.042 \pm 0.0089 \mathrm{~min}^{-1}$ ), whereas no change appeared in the placebo group during the same period $\left(\gamma_{2}=0.030 \pm 0.0087\right.$ versus $0.032 \pm 0.0060 \mathrm{~min}^{-1}$ ).

\section{Blood lactate concentrations during and after the 10 short cycling sprints}

- Fig. 2 a, b shows the kinetics of blood lactate concentration during the 10 sprints and during the first minutes of recovery in both groups. No significant difference was found in both groups in blood lactate concentration after the first, third, fifth, seventh and tenth sprint after treatment or placebo. However, as shown in 0 Fig. 2 a, significantly lower blood lactate $(p<0.05)$ was observed in the treatment group during the sprint recovery compared to the placebo group.

\section{Mitochondrial function}

As shown in $\odot$ Fig. 3, there was no significant effect of treatment $(p>0.05)$ on maximal muscle oxidative capacity. There was also no change in maximal respiration after cytochrome $\mathrm{c}$ addition. However, CS activity increased significantly in the treatment group after supplementation ( $\mathrm{p}<0.05)$ ( $\odot$ Fig. 4). No change appeared in the placebo group during the same period. A significant post-test difference $(p<0.05)$ was also detected between the treatment and placebo groups.

\section{Discussion \\ $\nabla$}

The originality of this study was to test a combination of several nutritional supplements included in protein hydrolysate and to study its combined effects on performance and fatigue level. The results of the current study suggest that after 28 days of treatment with protein hydrolysate enriched in branched chain amino acids and antioxidants, trace and mineral elements and vitamins, in athletes with different physical activity levels, (1) did not alter time limit exercise and supramaximal cycling performances, but (2) could delay fatigue appearance during continuous and intermittent supramaximal exercises, and (3) may induce some changes in parameters used to represent oxidative damage and antioxidant status, and lactate metabolism.

The results of the present study show that mean and peak power output were unchanged during supramaximal exercise in the 


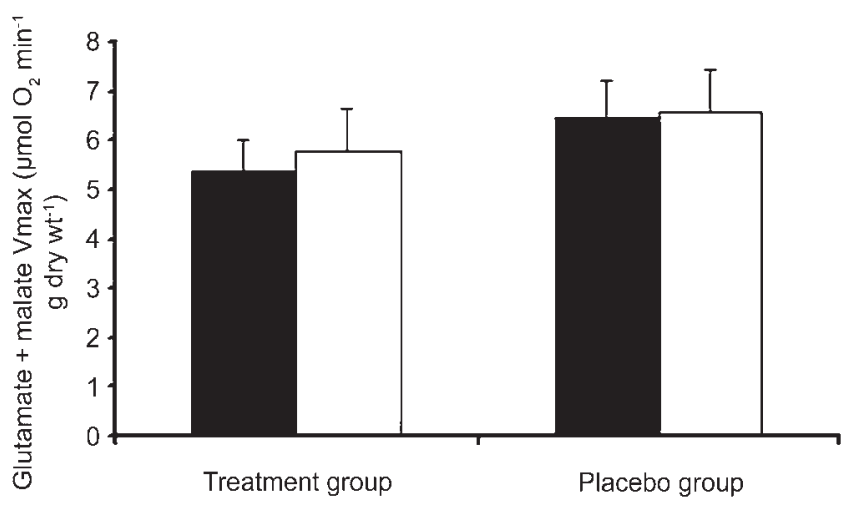

Fig. 3 Maximal muscle oxidative capacity $\left(\mu \mathrm{mol} \mathrm{O}_{2} \cdot \mathrm{min}^{-1} \cdot \mathrm{g} \cdot \mathrm{dry} \cdot \mathrm{wt}^{-1}\right)$ in saponin-permeabilized muscle fibers in pre- (black bars) and post-test (open bars) in the treatment $(n=7)$ and placebo $(n=7)$ groups.

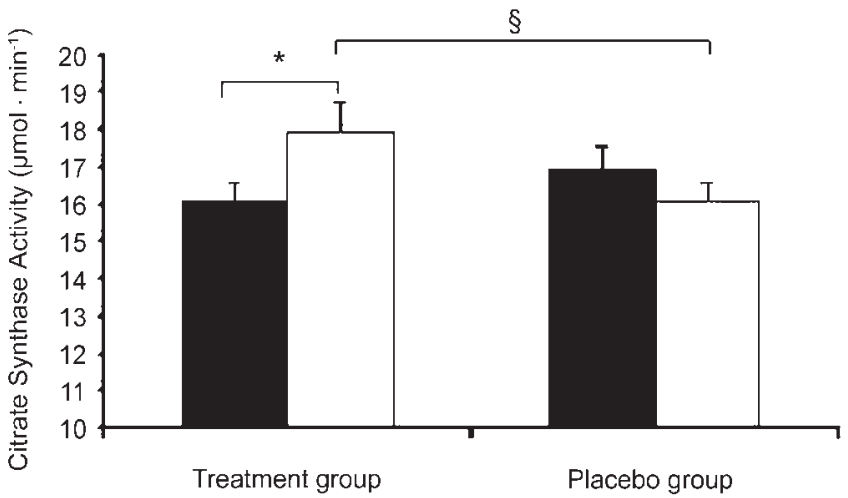

Fig. 4 Citrate synthase activity $\left(\mu \mathrm{mol} \cdot \mathrm{min}^{-1}\right)$ in pre- (black bars) and post-test (open bars) in the treatment $(n=9)$ and placebo $(n=9)$ groups. * Significant difference between pre- and post-test at $p<0.05$. $\S$ Significant difference between treatment and placebo groups in post-test at $p<0.05$. treatment and placebo groups. These results confirm the results of previous studies that have shown no effect of antioxidants [16] or BCAA supplementation [37] on physical anaerobic performance. However, fatigue indices were significantly lower after the supplementation $(\mathrm{p}<0.05)$ in the treatment group during both supramaximal exercise tasks, despite no change in peak power values during these tests, which confirmed the reproducibility of the procedure. Decrease in fatigue indices was in accordance with those of Vukovich et al. [37] who reported a small delayed fatigue during a 30-s Wingate test, but after only one week of protein treatment in untrained subjects. Consequently, changes in antioxidant potential and metabolic adaptations induced by 28 days of treatment could explain the delayed fatigue.

The treatment group presented a significantly lower oxidative damage production as indicated by TBARS and a higher GSH-PX activity in plasma at rest after supplementation than did the placebo group. The higher activity of resting plasma GSH-Px activity due to the seleno-dependent enzyme GSH-Px with treatment could be explained by the selenium contained in the mixture. This result is consistent with data on sedentary [27] and trained athletes [21] obtained after selenium supplementation. Furthermore, the mixture which contained a combination of several other antioxidants could also contribute to the decrease resting free radical production in plasma [21] observed in the treatment group. After the 1-min all-out supramaximal exercise, lipid peroxidation production, enzymatic and non-enzymatic antioxidants in plasma did not vary significantly in both groups. The oxidative stress was not great enough to change antioxidant status and increase plasma lipid peroxidation production in our physically-active athletes in contrast to strenuous long duration exercise or exhaustive sprint training observed in highly trained aerobic and sprint athletes [22]. Our results are consistent with those of Alessio et al. [1], who found no change in plasma free radical production after repeated isometric contractions and those of Ihara et al. [16] who did not find oxidative damage after anaerobic exercise in healthy subjects. As no significant variation of these previous biochemical parameters occurred in athletes after the 1-min all-out exercise, treatment had therefore no additional effect in the context of such an exercise. However, compared to sedentary persons, lower vitamin C and GSH plasma concentrations were found in athletes [2], as well as higher resting lipoperoxidation indices [22]. Treatment enriched in antioxidants could, therefore, have some favorable effects in athletes during training periods [21]. So, the treatment in the context of our study probably reinforced resting antioxidant potential against oxidative damage induced by chronic training. Other factors, such as the decrease in blood lactate concentration and changes in metabolic adaptations observed only in the treatment group, may account for the decrease in percent of fatigue as cellular acid-base disturbances have been closely linked with the fatigue process [9]. Indeed, increased lactate production coincides with cellular acidosis and remains a good indirect marker for cell metabolic conditions that induce metabolic acidosis [29] although lactate does not seem responsible for decreased muscle performance [17]. Then, after both the all-out and the 10 sprints cycling tests, significantly lower peak blood lactate concentrations $(p<0.05)$ were observed for the treatment group than for the placebo group. This finding is in agreement with those of Vukovich et al. [37] and De Palo et al. [8], who reported a decrease in blood lactate following a Wingate test and a 60min physical exercise at $75 \%$ of $\mathrm{VO}_{2 \max }$, respectively, when subjects consumed chronic amino acid supplements.

Although this finding would have been explained by a lower glycolytic activity, surprisingly, both previous studies observed a greater amount of alanine released during exercise, following a BCAA trial than a control trial. This alanine production, involving the addition of an amino acid group from glutamate issue of BCAA, to pyruvate, could be linked to lactate production, particularly when exhaustive exercise is carried out. Consequently, we can speculate that the lower lactate concentration at the end of the 1-min all-out test and the 10 short cycling sprints could be related to a lower accumulation of pyruvate because of its conversion into alanine or into acetyl-CoA, the latter participating in the tricarboxilic acid (TCA) cycle.

Increased BCAA availability [13] and metabolic acidosis [18] have been found to increase BCAA oxidation in rats and in humans. A lower blood lactate response and an enhanced clearance could be linked to increases in transamination of amino acids with pyruvate, increasing, therefore, oxidation of amino acids. In addition, BCAA are known to participate in a number of transamination reactions in skeletal muscle, not only among themselves, but also with glycolytic and TCA cycle intermediates (TCAI) in the mitochondria [4]. Acidosis affects the regulation of BCAA metabolism by enhancing flux through the transaminase 
and by directly stimulating oxidative catabolism through activation of branched-chain alpha-keto acid dehydrogenase. A better contribution of BCAA and pyruvate increasing TCAI could explain the significant increase of the CS activity measured in the treatment group ( Fig.4), although maximal muscle oxidative capacity was unaltered after treatment. The dissociation between CS activity and muscle maximal oxidative capacity has already been observed by Mettauer et al. [23], who showed a decrease of CS activity with an unaffected muscle maximal oxidative capacity in heart failure patients compared to sedentary men. The precise factors that regulate TCA cycle flux may vary depending on the metabolic situations and the relative importance of key intramitochondrial parameters such as the ATP/ $\mathrm{ADP}$ and $\mathrm{NAD}^{+} / \mathrm{NADH}$ ratios that can be influenced by the absolute concentration of specific TCAI [38]. However, several vitamins included in the treatment ( Table 2 ) are known to be cofactors of the different enzymatic reactions in the oxidative pathway, and may also contribute to the increase in TCAI flux. We also tested the effects of this nutritional supplement on time to fatigue at $\mathrm{VO}_{2 \max }$. Both groups did not show significant improvement in time to exhaustion at their $\dot{\mathrm{VO}}_{2 \max }$ on the treadmill ( Table 3) even if there was a light trend, but not significant, for the treatment group $(6.4 \pm 0.9$ min versus $7.2 \pm 1.3 \mathrm{~min})$. This confirmed the clear dissociation between the size of the TCAI pool, the capacity for oxidative energy delivery, and endurance exercise performance [15]. Others factors such as training effects, motivation, or biomechanical aspects could also interfere with the performance.

In conclusion, the present study demonstrated that nutritional treatment with protein hydrolysate enriched in branched chain amino acids and antioxidants, trace and mineral elements, and vitamins did not significantly improve time to fatigue at $\dot{\mathrm{VO}}_{2 \text { max }}$ or supramaximal exercise performance, but may promote a delayed fatigue appearance in two types of anaerobic exercise potentially explained by changes in parameters used to represent oxidative damage and antioxidant status at rest and changes in lactate metabolism.

\section{Acknowledgements}

The present study was supported by a Research Grant from Laboratoire Merck-Mf Richelet (Paris, France). The investigators thank the subjects for participating in our study. We greatly appreciate the help of Fabien Junius, Magali Bonnet, Marie-Chantal Granat, Anne Levasseur, and Denis Mottet. We also thank David Bishop for his english correction.

\section{References}

1 Alessio HM, Hagerman AE, Fulkerson BK, Ambrose J, Rice RE, Wiley RL. Generation of reactive oxygen species after exhaustive aerobic and isometric exercise. Med Sci Sports Exerc 2000; 32: 1576- 1581

2 Balakrishnan SD, Anuradha CV. Exercise, depletion of antioxidants and antioxidant manipulation. Cell Biochem Funct 1998; 16: 269-275

3 Bergman BC, Horning MA, Casazza GA, Wolfel EE, Butterfield GE, Brooks $G A$. Endurance training increases gluconeogenesis during rest and exercise in men. Am J Physiol 2000; 278: E244 -E251

4 Brooks GA. Amino acid and protein metabolism during exercise and recovery. Med Sci Sports Exerc 1987; 19: S150-S156

5 Brotherhood JR. Nutrition and sports performance. Sports Med 1984; 1 : $350-389$

6 Cachia O, Leger CL, Boulot P, Vernet MH, Michel F, Crastes de Paulet A, Descomps $B$. Red blood cell vitamin E concentrations in fetuses are related to but lower than those in mothers during gestation. A possible association with maternal lipoprotein (a) plasma levels. Am J Obstet Gynecol 1995; 173: $42-51$

7 Clarkson PM, Thompson HS. Antioxidants: what role do they play in physical activity and health? Am J Clin Nutr 2000; 72: 637S-646S

8 De Palo EF, Gatti R, Cappellin E, Schiraldi C, De Palo CB, Spinella P. Plasma lactate, $\mathrm{GH}$ and $\mathrm{GH}$-binding protein levels in exercise following BCAA supplementation in athletes. Amino Acids 2001; 20: 1 - 11

9 Fitts RH. Muscle fatigue: the cellular aspects. Am J Sports Med 1996; 24: S9-S13

10 Flohe L, Gunzler WA. Assays of glutathione peroxidase. Meth Enzymol 1984; 105: $114-121$

11 Freund H, Gendry P. Lactate kinetics after short strenuous exercise in man. Eur J Appl Physiol 1978; 39: 123-135

12 Freund $H$, Lonsdorfer J, Oyono-Enguelle S, Lonsdorfer A, Bogui P. Lactate exchange and removal abilities in sickle cell patients and in untrained and trained healthy humans. J Appl Physiol 1992; 73: 2580-2587

13 Freund HR, Hanani M. The metabolic role of branched-chain amino acids. Nutrition 2002; 18: $287-288$

14 Gutmann I, Wahlefeld AM. L-(+)-lactate determination with lactate dehydrogenase and NAD. Methods of Enzymatic Analysis. NY: Academic Press, 1974: 1464 - 1472

15 Howarth KR, LeBlanc PJ, Heigenhauser GJ, Gibala MJ. The effect of endurance training on muscle TCA cycle metabolism during exercise in humans. J Appl Physiol 2004; 97: 579-584

16 Ihara H, Shino Y, Morita Y, Kawaguchi E, Hashizume N, Yoshida M. Is skeletal muscle damaged by the oxidative stress following anaerobic exercise? J Clin Lab Anal 2001; 15: 239-243

17 Lamb GD, Stephenson DG, Bangsbo J, Juel C. Point: counterpoint: lactic acid accumulation is an advantage/disadvantage during muscle activity. J Appl Physiol 2006; 100: 1410-1412

18 Letellier T, Malgat M, Coquet M, Moretto B, Parrot-Roulaud F, Mazat JP. Mitochondrial myopathy studies on permeabilized muscle fibers. Pediatr Res 1992; 32: 17-22

19 Lukaski HC, Johnson PE, Bolonchuch WW, Lykken L. Assessment of fat free mass using bioelectrical impedance measurements of the human body. Am J Clin Nutr 1985; 41: 810-817

20 MacLean DA, Graham TE, Saltin B. Stimulation of muscle ammonia production during exercise following branched-chain amino acid supplementation in humans. J Physiol 1996; 493: 909-922

21 Margaritis I, Palazzetti S, Rousseau AS, Richard MJ, Favier A. Antioxidant supplementation and tapering exercise improve exercise-induced antioxidant response. J Am Coll Nutr 2003; 22: 147-156

22 Marzatico F, Pansarasa O, Bertorelli L, Somenzini L, Della Valle G. Blood free radical antioxidant enzymes and lipid peroxides following longdistance and lactacidemic performances in highly trained aerobic and sprint athletes. J Sports Med Phys Fitness 1997; 37: 235-239

23 Mettauer B, Zoll J, Sanchez H, Lampert E, Ribera F, Veksler V, Bigard X, Mateo P, Epailly E, Lonsdorfer J, Ventura-Clapier R. Oxidative capacity of skeletal muscle in heart failure patients versus sedentary or active control subjects. J Am Coll Cardiol 2001; 38: 947-954

24 Mourier A, Bigard AX, de Kerviler E, Roger B, Legrand H, Guezennec CY. Combined effects of caloric restriction and branched-chain amino acid supplementation on body composition and exercise performance in elite wrestlers. Int J Sports Med 1997; 18: 47-55

25 Mourtzakis M, Graham TE. Glutamate ingestion and its effects at rest and during exercise in humans. J Appl Physiol 2002; 93: 1251 -1259

26 Nemet D, Wolach B, Eliakim A. Proteins and amino acid supplementation in sports: are they truly necessary? Isr Med Assoc J 2005; 7 : $328-332$

27 Preziosi P, Galan P, Herbeth B, Valeix P, Roussel AM, Malvy D, Paul-Dauphin A, Arnaud J, Richard MJ, Briancon S, Favier A, Hercberg S. Effects of supplementation with a combination of antioxidant vitamins and trace elements, at nutritional doses, on biochemical indicators and markers of the antioxidant system in adult subjects. J Am Coll Nutr 1998; 17: $244-249$

28 Ratel S, Duche P, Hennegrave A, Van Praagh E, Bedu M. Acid-base balance during repeated cycling sprints in boys and men. J Appl Physiol 2002; 92: 479-485

29 Robergs RA, Ghiasvand F, Parker D. Biochemistry of exercise-induced metabolic acidosis. Am J Physiol 2004; 287: R502 - R516

30 Saks VA, Veksler VI, Kuznetsov AV, Kay L, Sikk P, Tiivel T, Tranqui L, Olivares J, Winkler K, Wiedemann F, Kunz WS. Permeabilized cell and skinned fiber techniques in studies of mitochondrial function in vivo. Mol Cell Biochem 1998; 184: 81 - 100

31 Srere P. Citrate synthase. Meth Enzymol 1969; 13: 3 -5 
32 Striegel H, Simon P, Wurster C, Niess AM, Ulrich R. The use of nutritional supplements among master athletes. Int J Sports Med 2006; 27: 236 241

33 Sundgot-Borgen J, Berglund B, Torstveit MK. Nutritional supplements in Norwegian elite athletes - impact of international ranking and advisors. Scand J Med Sci Sports 2003; 13: $138-144$

34 Thomas C, Perrey S, Lambert K, Hugon G, Mornet D, Mercier J. Monocarboxylate transporters, blood lactate removal after supramaximal exercise and fatigue indexes in humans. J Appl Physiol 2005; 98: 804-809

35 Thomas C, Sirvent P, Perrey S, Raynaud E, Mercier J. Relationships between maximal muscle oxidative capacity and blood lactate removal after supramaximal exercise and fatigue indexes in humans. J Appl Physiol 2004; 97: 2132-2138

36 van Hall G, MacLean DA, Saltin B, Wagenmakers AJ. Mechanisms of activation of muscle branched-chain alpha-keto acid dehydrogenase during exercise in man. J Physiol 1996; 494: 899-905

37 Vukovich MD, Sharp RL, King DS, Kershishnik K. The effect of protein supplementation on lactate accumulation during submaximal and maximal exercise. Int J Sport Nutr 1992; 2: 307-316

38 Williamson JR, Cooper RH. Regulation of the citric acid cycle in mammalian systems. FEBS Lett 1980; 117 (Suppl): K73 - K85

39 Yagi K. A simple fluorometric assay for lipoperoxide in blood plasma. Biochem Med 1976; 15: 212-216 